\title{
"SEM RÉGUA E ESQUADRO" \\ DESAFIOS E OPORTUNIDADES DA INVESTIGAÇÃO SOBRE TEMAS SENSÍVEIS E COM GRUPOS VULNERÁVEIS
}

\author{
"WITHOUT A RULER AND A SQUARE" \\ CHALLENGES AND OPPORTUNITIES OF RESEARCH ON \\ SENSITIVE TOPICS AND WITH VULNERABLE POPULATIONS
}

\author{
Fábio Rafael Augusto \\ Instituto de Ciências Sociais, Universidade de Lisboa. Av. Professor Aníbal de Bettencourt 9, 1600-189 Lisboa, \\ Portugal. Email: fabio.augusto@ics.ulisboa.pt
}

\begin{abstract}
Resumo: Realizar investigação sobre temas sensíveis e com grupos vulneráveis acarreta um conjunto de desafios e implica pensar sobre o desenho de pesquisa de forma a responder aos mesmos. O presente artigo procura dar a conhecer uma experiência de investigação que incide na análise de iniciativas de apoio alimentar a atuar no contexto nacional e dos seus atores (voluntários e beneficiários). São discutidas diversas estratégias que foram sendo tomadas durante o trabalho de campo que contou com a realização de observação participante através da prática de voluntariado e a condução de entrevistas semiestruturadas. Desta forma, e com base numa análise crítica e reflexiva, explora-se o acesso ao terreno, o estatuto de voluntário, a gestão das emoções e a aplicação do consentimento informado num contexto marcado pela sensibilidade e vulnerabilidade. Espera-se, assim, contribuir para a discussão de abordagens que podem ser adotadas no âmbito deste tipo de pesquisa.
\end{abstract}

Palavras-chave: temas sensíveis, grupos vulneráveis, iniciativas de apoio alimentar, pobreza alimentar.

\begin{abstract}
Conducting research on sensitive topics and with vulnerable populations entails a set of challenges and that imply thoroughly thinking about research design in order to respond to such challenges. This article presents a research experience focused on the analysis of food aid initiatives operating in Portugal and on its actors (volunteers and food aid recipients). The several strategies that were adopted during the fieldwork, namely participant observation through the practice of volunteering and semi-structured interviews, are discussed. Drawing on a critical and reflexive analysis, aspects such as access to the field, volunteer status, management of emotions and application of informed consent in a context marked by sensitivity and vulnerability are explored. Thus, this article contributes to the discussion of approaches that can be mobilized in this kind of research.
\end{abstract}

Keywords: sensitive topics, vulnerable populations, food aid initiatives, food poverty.

\section{Introdução}

Levar a cabo um projeto de investigação representa um desafio, podendo ser interpretado como um puzzle que cabe ao investigador resolver, se associarmos a sensibilidade do tema e a vulnerabilidade dos participantes, o número de peças aumenta consideravelmente e o quebra-cabeça torna-se mais complexo. 
O presente artigo visa, justamente, dar a conhecer um puzzle específico, mas que apresenta desafios transversais a várias investigações que se desenvolvem no âmbito das ciências sociais. O projeto de doutoramento em causa assenta na análise das dinâmicas que se encontram presentes na relação que se estabelece entre voluntários e beneficiários de iniciativas de apoio alimentar (IAA's) a atuar no contexto nacional. Através desta análise, será possível partir para a identificação dos pontos fortes e fragilidades que caracterizam estas respostas e pensar em estratégias que as permitam adequar às necessidades dos seus principais intervenientes.

A vertente qualitativa da metodologia mista seguida na investigação assentou, numa primeira fase, na realização de voluntariado junto das IAA's, o que permitiu, através da técnica de observação participante, chegar às dinâmicas em causa e criar proximidade com voluntários e beneficiários para que, numa segunda fase, se realizassem entrevistas semiestruturadas.

Como se poderá perceber, com base nesta breve descrição do projeto em curso, ele incide sobre um tema sensível - pobreza alimentar - e um grupo vulnerável - beneficiários de IAA's - que enfrenta, em diversos casos, processos de exclusão, rotulagem e estigmatização.

Face a este duplo nível de dificuldade - sensibilidade do tema e vulnerabilidade dos participantes - emerge, durante todo o processo de pesquisa, um alargado leque de questões que se prendem com a forma como o investigador pode enquadrar a sensibilidade e vulnerabilidade no seu projeto. Desta forma, no presente artigo procurar-se-á responder a questões como: O que são temas sensíveis e grupos vulneráveis? Que tipo de desafios podemos encontrar face à sensibilidade dos temas e à vulnerabilidade dos participantes? Que respostas podem ser dadas face a tais desafios?

Para tal, o artigo encontra-se estruturado em torno de três secções. Na primeira, é apresentado o projeto de investigação que suscitou alguns dos debates que aqui se apresentam. Na segunda, são explorados e analisados os conceitos de tema sensível e grupo vulnerável. Na terceira, são dados a conhecer alguns dos desafios com que o investigador se deparou, bem como a forma como enfrentou os mesmos.

\section{O projeto: As iniciativas de apoio alimentar e os seus atores}

O projeto de investigação, iniciado em 2016, surge associado à necessidade de compreender, de forma aprofundada, uma realidade que tem alimentado debates em diversas esferas da vida social.

De facto, as IAA's constituem um campo fértil de análise, pela transversalidade e centralidade que têm vindo a assumir em diferentes contextos sócio históricos. Contudo, e apesar do vasto conjunto de recursos humanos e financeiros que têm 
vindo a mobilizar ao longo dos tempos e, particularmente, em momentos de crise económica, as perspetivas em torno destas iniciativas não reúnem consenso.

Se, por um lado, se considera que as iniciativas de apoio alimentar têm contribuído para combater a pobreza e a insegurança alimentar, por outro, elas têm vindo a ser alvo de múltiplas críticas, geralmente, relacionadas com os custos para a dignidade humana, com a dependência gerada e com a inadequação nutricional dos alimentos doados. Além disso, os debates promovidos em torno das IAA's tendem a apontar a ausência de respostas estruturais pensadas a longo prazo que permitam, de forma eficaz, a erradicação dos problemas que visam combater e a emancipação das "vítimas" dos mesmos (Mirosa, Mainvil, Horne e Magan-Walker, 2016; Van der Horst, Pascucci e Bol, 2014; Vlaholias, Thompson, Every e Dawson, 2015).

É, justamente, desta aparente incompatibilidade - o crescimento/expansão das IAA's e as ineficiências que lhes têm vindo a ser apontadas - que surge o projeto em causa. Assim, interessa perceber como se regulam estas iniciativas no contexto atual. Tal compreensão permitirá dar a conhecer, por um lado, o porquê da sua permanência e, por outro, o porquê das suas críticas. Para tal, o presente projeto assenta no olhar de quatro atores: i) investigador; ii) beneficiários; iii) voluntários; e iv) responsáveis das iniciativas.

Tais olhares foram obtidos com o recurso a uma metodologia predominantemente qualitativa ${ }^{1}$. Através da prática de voluntariado e da técnica de observação participante, durante, aproximadamente, três meses em cada uma das IAA's analisadas (Re-food, Cantina Social e Mercearia Social), o investigador explorou o funcionamento, bem como as dinâmicas presentes na relação voluntário-beneficiário. Numa segunda fase, foram conduzidas 39 entrevistas semiestruturadas aos voluntários (18), aos beneficiários (18) e aos responsáveis pelas iniciativas (3).

Durante o processo de negociação de entrada no terreno foi dado a conhecer o projeto (as várias fases, os objetivos e os instrumentos de recolha de dados) e assinado um protocolo de cooperação com os responsáveis das iniciativas onde se garantiu a confidencialidade dos dados e o anonimato dos participantes.

O trabalho de campo foi concluído em março de 2019. Atualmente, o investigador encontra-se a tratar os dados recolhidos, nomeadamente, transcrição e análise das entrevistas e das notas de campo recolhidas com recurso a gravador digital.

\section{Da sensibilidade à vulnerabilidade: Os contornos dos conceitos}

No âmbito da investigação em ciências sociais existem temáticas que, de forma relativamente simples e imediata, são apelidadas de sensíveis, porém, como se estabelecem os critérios para incluir uma temática nesta categoria? 
Diversos esforços foram realizados no sentido de fornecer uma resposta a esta questão, existindo um debate acesso e um alargado leque de definições que se inserem numa espécie de continuum que vai desde conceptualizações focadas no tema da investigação até definições que englobam toda a atividade de pesquisa e se preocupam com as implicações para prática científica e os seus intervenientes (Dickson-Swift, James e Liamputtong, 2008; Martins, Oliveira e Tendais, 2018).

Tal como é referido por Hennequin e Condomines (2014), durante muito tempo, o conceito de tema sensível esteve associado a questões tabu, ou seja, a tópicos com uma forte carga emocional, geralmente, negativa que eram, de alguma forma, sancionados pela sociedade de forma a evitar certos comportamentos. Contudo, esta associação é demasiado restritiva, uma vez que nem todos os temas sensíveis são tabus e uma vez que a sensibilidade é contextual, podendo surgir de um tema aparentemente inócuo.

Sieber e Stanley (1988) lançam uma definição mais abrangente ao referirem que podemos estar na presença de um tema sensível se existirem consequências ou implicações para os atores investigados ou o seu grupo de pertença. Mais tarde, Lee e Renzetti (1990) viriam contribuir para o aprofundamento desta definição, identificando um conjunto específico de custos, nomeadamente, custos psicológicos; custos que possam advir do desenrolar da pesquisa e custos relacionados com os desafios que podem colocar em causa a relação investigador-investigado.

Lee e Renzetti (1990, p. 512 - tradução livre) avançaram também com algumas áreas que previam serem mais ameaçadoras e criadoras de vulnerabilidade no ator investigado do que outras, nomeadamente, no caso de estudos que:

i) entrem na esfera privada ou incidam de forma aprofundada sobre a experiência pessoal; ii) se centrem em questões relacionadas com o desvio e controlo social; iii) abordem questões de poder e que podem envolver dinâmicas de coerção e de dominação; e iv) incidam sobre algo que o agente estudado considera sagrado e, portanto, não quer ver profanado.

Seguindo a mesma linha de pensamento, Wellings, Branigan e Mitchell (2000, p. 5 - tradução livre) afirmam que estamos perante uma investigação sobre temas sensíveis "se levar à exposição de comportamentos ou atitudes que: i) normalmente, seriam mantidos na esfera privada; ii) podem resultar em ofensas, censura social ou desaprovação; e iii) podem causar desconforto ao ator investigado".

Entre os mais variados exemplos de temáticas que têm vindo a ser caracterizadas como sendo sensíveis, encontra-se a pobreza. De acordo com Schweiger e Graf (2015) falar sobre pobreza, particularmente no âmbito de uma pesquisa qualitativa, implica que se abordem assuntos do foro privado. Ademais, a sensibilidade 
da temática tende a estar ligada e a despertar "raiva, vergonha e humilhação" (Schweiger e Graf, 2015, p. 2 - tradução livre).

De facto, abordar questões relacionadas com a pobreza e, particularmente, com a pobreza alimentar pode conduzir à emergência de diversas emoções que causem algum tipo de desconforto ao indivíduo que é confrontado com as mesmas. A experiência de pobreza está associada a histórias de vida marcadas pela existência de múltiplos obstáculos (ex: desemprego) e privações (ex: alimentares). Abordar tais histórias, por exemplo, em contexto de entrevista conduz, inevitavelmente, o sujeito a pensar sobre a sua condição "de pobre", criando um momento reflexivo que pode causar incómodo. Além disso, e apesar dos extensos debates em torno das causas estruturais da pobreza (ver Calnitsky, 2018) é possível encontrar fenómenos de culpabilização da "vítima", onde emergem processos de rotulagem, estigmatização e exclusão (Van der Horst, Pascucci e Bol, 2014).

Se, por um lado, a pobreza pode ser inserida na categoria de tema sensível, por outro, aqueles que a experienciam podem ser caracterizados como vulneráveis. Tal como o conceito de tema sensível, também o conceito de grupo vulnerável possui múltiplas definições (Liamputtong, 2007). Silva (1995, p. 15 - tradução livre) refere que a vulnerabilidade estará presente em pessoas que vêm a sua "autonomia ser reduzida devido a fatores fisiológicos/psicológicos ou a desigualdades sociais". Mais tarde, Moore e Miller (1999, p. 1034 - tradução livre) viriam a apresentar a seguinte definição: "os indivíduos considerados vulneráveis são aqueles que não têm capacidade para fazer escolhas ou tomar decisões sobre a sua vida, para manter a sua independência, e para se autodeterminar".

Tais conceptualizações possibilitam a inserção dos beneficiários de IAA's na categoria de grupo vulnerável, na medida em que a autonomia daqueles que recorrem a ajuda alimentar é fortemente restringida devido, sobretudo, às dificuldades financeiras que enfrentam, o que condiciona as suas escolhas em torno da sua alimentação e, em certos casos, da alimentação da família. Por se tratar de um grupo com fortes carências alimentares que condicionam o seu bem-estar físico e psicológico, geralmente, a vulnerabilidade é caracterizada como extrema (Loopstra e Lalor, 2017).

Depa, Gyngell, Muller, Eleraky, Hilzendegen e Stroebele-Benschop (2018) caracterizam os beneficiários de IAA's não só como pertencentes a um grupo vulnerável, mas também a uma "população socialmente desfavorecida", reforçando assim a ligação entre vulnerabilidade e desigualdade social, previamente enunciada por Silva (1995).

Apesar de se considerar que nem todos os beneficiários são iguais e enfrentam os mesmos desafios ou os mesmos níveis de vulnerabilidade, trata-se de um 
grupo que tende a partilhar certas características, como os baixos rendimentos auferidos ou a inexistência dos mesmos, a situação de desemprego ou a permanência em empregos com baixos salários e o recurso a apoio estatal (ex. subsídios). É um grupo que, geralmente, enfrenta diversos problemas de saúde e leva a cabo uma alimentação considerada nutricionalmente desadequada (Stroebele-Benschop, Simmet e Depa, 2017).

Tal como é referido por Johnson e Clarke (2003), existe uma relação forte entre a sensibilidade dos temas e a vulnerabilidade dos participantes, sendo que investigar um tema sensível pode conduzir ao contacto com pessoas ou grupos considerados vulneráveis e vice-versa. Esta combinação traz consigo um conjunto alargado de questões, algumas delas serão analisadas nos pontos que se seguem, onde se procurará dar conta da importância de englobar a vulnerabilidade e sensibilidade nas várias fases do processo de pesquisa (Lee e Ranzetti, 1990; Martins, Oliveira e Tendais, 2018; Seigel e Bauman, 1986; Sieber e Stanley, 1988).

\section{Desafios associados à investigação que incide sobre temas sensíveis e grupos vulneráveis}

Conduzir uma investigação, independentemente do assunto tratado ou dos métodos aplicados, acarreta responsabilidades e desafios (Marsh, Browne, Taylor e Davis, 2017, p. 63 - tradução livre)

Sejam os desafios, enunciados por Marsh, Browne, Taylor e Davis (2017), de ordem metodológica, ética, filosófica, política ou legal, cabe ao investigador pensar sobre os mesmos de forma crítica e reflexiva e tomar decisões (Lee e Ranzetti, 1990; Marsh, Browne, Taylor e Davis, 2017). Cada investigação possui elementos caracterizadores que a tornam singular, conduzindo assim o investigador a procurar as suas próprias respostas e estratégias.

A pesquisa que incide sobre temas sensíveis e grupos vulneráveis, por implicar incorporar em todas as fases do processo de pesquisa a sensibilidade e a vulnerabilidade e, portanto, por acrescentar algo a um exercício que, já por si, é complexo, pode afastar investigadores.

A este respeito, Duelli-Klein (1983) defende que a questão: "O que estudar?" deve anteceder a questão: "Como estudar?", reforçando assim a ideia de que a reflexão em torno da estratégia metodológica a seguir deve ser posterior à decisão dos temas ou dos assuntos que se querem tratar e, de certa forma, acaba também por reforçar a ideia de que a decisão sobre a escolha do tema deve ser, numa primeira fase, independente das escolhas em torno da operacionalização do mesmo. Tal 
separação pode assim contribuir para evitar o afastamento anteriormente referido, permitindo ao investigador abster-se, numa primeira fase, de limitar as suas escolhas devido a restrições de ordem metodológica.

Contudo, pensar simultaneamente sobre o tema e sobre a sua operacionalização permite ao investigador avaliar não só a pertinência da investigação como também a exequibilidade da mesma. Tendo em conta o planeamento prévio que é exigido aos investigadores quando os mesmos procuram financiamento junto de uma instituição pública ou privada, os dois pensamentos em causa tornam-se, praticamente, indissociáveis.

Um outro aspeto a ter em conta quando se parte para o tipo de investigação em causa prende-se com o impacto que a mesma pode ter para os participantes e para o próprio investigador (Vincett, 2018). Mais do que ser capaz de cumprir os objetivos da investigação, o investigador deve ser capaz de o fazer sem prejudicar o bem-estar dos atores envolvidos. Ainda que as repercussões que este tipo de investigação pode assumir não sejam fáceis de avaliar, é certo que a sensibilidade e a vulnerabilidade acarretam um acrescido número de responsabilidades ao investigador.

Porém, este tipo de investigação é de extrema importância, fundamentalmente, por permitir dar voz a quem nem sempre tem capacidade para se fazer ouvir e para que se possam tomar medidas que vão ao encontro das reais necessidades da população que é alvo de estudo (Dickson-Swift, James e Liamputtong, 2008; Lee e Renzetti, 1993; Sieber e Stanley, 1988).

Uma forma de colmatar alguns dos desafios inerentes ao processo de investigação e ao carácter singular que os mesmos assumem prende-se com a partilha de experiências entre investigadores (Augusto e Hilário, 2019; Vincett, 2018). Esta estratégia é, particularmente, útil no caso da investigação que incide sobre temas sensíveis e grupos vulneráveis.

Desta forma, o presente artigo procura, justamente, através da partilha de uma experiência de investigação e, portanto, dos elementos que a tornam singular e dos que a tornam semelhante a tantas outras, contribuir para a análise crítica e reflexiva das práticas de investigação à luz dos conceitos supramencionados (temas sensíveis e grupos vulneráveis). Para tal, apresentam-se e exploram-se de seguida quatro desafios relacionados com os conceitos em análise.

\section{O acesso ao terreno}

Quando o investigador se encontra a planear o seu projeto de investigação e começa a focar na operacionalização do mesmo e, portanto, nas questões metodológicas, várias interrogações emergem, onde se destaca: Como vou aceder ao terreno de pesquisa? Trata-se de uma questão importante na medida em que é este terreno 
que permite a obtenção dos dados que irão "alimentar" possíveis perguntas de partida ou hipóteses de investigação.

Tal como é referido por Amante (2015), a decisão em torno da escolha do terreno pode tornar-se numa fase stressante, não só pela dificuldade em torno da delimitação do mesmo, mas também pelos obstáculos ligados ao seu acesso.

Se é expectável que o investigador tenha preocupações relacionadas com a sensibilidade do tema e a vulnerabilidade dos participantes e, particularmente, com a forma como irá conseguir compatibilizar estes desafios com o cumprimento dos objetivos de pesquisa, também é expectável que as instituições que acolhem indivíduos vulneráveis tenham reticências em abrir as suas portas para investigadores. O receio da instituição passar uma imagem negativa que possa colocar em causa a sua credibilidade e ainda a existência de preocupações relacionadas com a capacidade do investigador em garantir o bem-estar dos participantes pode condicionar o acesso ao terreno.

A este respeito, Waddington (1994), Mulhall (2003) e Bryman (2012) enaltecem a importância de saber negociar a entrada no terreno, podendo tratar-se, em diversos casos, e dependendo do objeto de estudo, de um processo demorado e complexo. Além disso, este processo de negociação começa no momento em que se define o objeto de estudo e a forma como se pode chegar a ele (Gold, 1997), ou seja, pensar sobre os espaços e lugares onde a observação vai ocorrer envolve pensar $a$ priori na questão do acesso.

Refletir sobre esta etapa implica, desde logo, antecipar cenários e traçar estratégias. Implica, por exemplo, ter em conta a existência de hierarquias no seio das instituições que podem condicionar a negociação e atrasar a mesma (Mulhall, 2003), podendo inviabilizar um qualquer cronograma que o investigador procure seguir e colocando em causa etapas de investigação posteriores.

Antecipando estes e outros problemas, considerou-se pertinente recorrer à prática de voluntariado como forma de aceder às IAA's. Trata-se de uma estratégia que tem vindo a ser utilizada por diversos investigadores (Martin, 2014; Merrell e Williams, 1994; Watts, 2011) e que permite aceder a vários tipos de instituições. Esta estratégia possibilitaria assim entrar nas IAA's e recolher os dados necessários oferecendo algo em troca, neste caso, o tempo do investigador em prol das necessidades das organizações em causa. Desta forma, o investigador tem a possibilidade de retribuir de forma imediata, representando uma alternativa viável para aceder ao terreno ( $\mathrm{O}^{\prime}$ Connor e Baker, 2017).

Após esta decisão, o investigador partiu para o terreno e para aquilo que designou por período exploratório, onde mais do que recolher dados, interessava perceber o funcionamento das IAA's e o que seria necessário para negociar a entrada. 
Durante este período estabeleceu-se que seria criado um protocolo de cooperação com as IAA's de forma a garantir, por um lado, que as iniciativas acolhiam o investigador e mediavam a interação do mesmo com a IAA e os seus atores; e por outro, que o investigador disponibilizasse o seu tempo em prol da organização.

Além do protocolo, também se estabeleceu que a IAA receberia um folheto explicativo do projeto; o modelo de consentimento informado que seria aplicado aos participantes; uma declaração por parte da Comissão de Ética do instituto que acolhe o projeto de investigação em causa a atestar que foram tomadas todas as diligências necessárias e cumpridos os princípios éticos em vigor; e uma declaração por parte dos responsáveis pelo doutoramento a dar conta da sua existência e objetivos. Estes documentos permitiram, não só, legitimar o discurso do investigador e a sua pesquisa, como também satisfazer as necessidades que as instituições, em geral, têm de prestar contas aos mais diversos tipos de stakeholders.

No contacto com o terreno, o investigador deparou-se, como seria de esperar, com diferentes posturas e exigências por parte das IAA's. De forma a salvaguardar as iniciativas envolvidas, elas não serão identificadas nesta secção (o acesso ao terreno).

No contacto com duas das três IAA's pertencentes ao estudo, o processo de negociação ocorreu de forma fluída, todos os documentos previamente referidos foram entregues e devidamente assinados e o início do trabalho de campo deu-se pouco tempo depois do primeiro contacto.

Na outra IAA, o processo de negociação foi mais demorado e complexo, a existência de uma hierarquia bem definida e de uma multiplicidade de procedimentos burocráticos acabaria por condicionar a negociação. O contacto com o responsável deu-se, numa fase inicial, de forma mediada, e só passado algum tempo (semanas) foi possível contactar diretamente com o próprio. Não só foi exigido ao investigador todos os documentos referidos, como também a disponibilização dos resultados de investigação aquando do fim da mesma. Em prol da continuidade da pesquisa, o investigador acabaria por ceder. Contudo, e após o contacto com o terreno, a IAA viria a tornar-se mais flexível e a pedir "apenas" alguns dos dados a ser publicados em tese que dizem respeito às notas de campo.

Das três IAA's envolvidas, duas questionaram o investigador sobre as suas capacidades para lidar com a vulnerabilidade que iria encontrar. Aqui o fator idade poderá ter pesado, uma vez que o investigador é relativamente novo (27 anos aquando do trabalho de campo) e que, no senso comum, isto se pode traduzir em inexperiência. Aqui o recurso aos documentos informativos e a um discurso assertivo em torno daquilo que iria ser realizado no âmbito da investigação permitiram transmitir confiança aos responsáveis. 
O investigador deixou claro que a vulnerabilidade dos participantes e a sensibilidade do tema estavam considerados no âmbito do seu projeto de investigação e, portanto, tratava-se de aspetos que haviam sido ponderados. Neste sentido, foi explicado aos responsáveis, por exemplo, que o recurso à observação participante permitiria criar proximidade com os participantes e que as entrevistas semiestruturadas só seriam aplicadas a quem manifestasse aceitar colaborar e estivesse a par dos objetivos do projeto.

Estas experiências mostram, por um lado, que o investigador deve preparar-se antes de partir para o processo de negociação - indo, em fase exploratória, ao terreno e perceber quais poderão vir a ser as necessidades que poderá vir a ter de dar resposta - e, por outro, que o investigador se deve adaptar a diferentes exigências e ter a capacidade para defender o seu projeto face às dúvidas que os responsáveis possam colocar.

\section{O estatuto de voluntário: Uma observação a dois níveis}

Tal como foi referido anteriormente, a possibilidade de observar as lógicas internas de uma determinada organização através da articulação entre a observação participante e a prática de voluntariado constitui uma estratégia que opera numa lógica de reciprocidade, representando uma alternativa viável, quer para os investigadores, que se sentem a retribuir, quer para as organizações, que vêm algum retorno imediato.

Ao tratar-se de uma técnica (observação participante) e de uma prática (voluntariado) que permitem observar as interações à medida que ocorrem, o investigador ganha um acesso privilegiado às dinâmicas que ocorrem tanto no palco como nos bastidores, recorrendo a um discurso "Goffmaniano" (Berger, 2017; Burgess, 1997). Recolhe-se, portanto, informação de forma direta, sem que alguém a tenha relatado ao investigador.

Um dos fatores que poderá condicionar a prossecução da técnica prende-se com os elementos caracterizadores do próprio investigador. Desta forma, elementos como a posição social, a idade e o sexo podem influenciar no contacto com o terreno e com os seus atores (Berger, 2017). Na investigação em causa, o fato do investigador ser um homem branco de classe média próximo dos 30 anos parece ter contribuído para criar afastamento com alguns voluntários e beneficiários. O fator idade e sexo foram os elementos que, de forma mais visível, influenciaram as observações. Frases como "ainda és muito novo", "tens pouca experiência de vida" e "quem sofre sempre mais são as mulheres...os homens não percebem" acabaram por limitar alguns diálogos, dando conta da influência que os elementos caracterizados do observador podem adquirir. 
Além disso, o nível de imersão e de envolvimento variou consoante o grupo que era observado. Face ao duplo nível de observação, foi possível encontrar diferenças significativas na relação que o investigador, enquanto voluntário, desenvolveu com os dois grupos com que interagiu (voluntários e beneficiários).

O processo de integração ocorreu de forma mais fluida junto dos voluntários, fundamentalmente, pelo papel assumido e funções desempenhadas pelo investigador (Spradley, 1980) que o conduziam a passar a maior parte do tempo de voluntariado com este grupo. Perante o grupo dos beneficiários, o nível de imersão foi menor, devido, sobretudo, às restrições impostas pelo trabalho voluntário, que conduziam o investigador a limitar a sua interação. A necessidade de servir o maior número de pessoas de forma rápida, acabou por condicionar, em certos momentos, o contacto com os beneficiários.

Além disso, ao não estar na mesma situação (desfavorecida) dos beneficiários e ao não vivenciar as suas experiências, o investigador, enquanto voluntário, pode ser visto como "um dos outros". Também a existência de conflitos entre os dois grupos e a desconfiança generalizada que alguns beneficiários apresentam, em diversos casos, como resultado da existência de histórias de vida marcadas pelo abandono, pela violência física e psicológica, pela pobreza e/ ou pela exclusão, poderão ter contribuído para condicionar a integração do investigador.

Se, por um lado, o estatuto permitiu entrar nas IAA's e criar proximidade com os voluntários, por outro, pode colocar em causa a relação que se estabelece com os beneficiários. Isto levanta, desde logo, uma questão que se prende com a forma como se pode compatibilizar a prossecução do trabalho de campo com o distanciamento que o estatuto de voluntário aparenta criar.

Apercebendo-se desta situação, o investigador optou por, sempre que possível, dar a conhecer o seu duplo papel na iniciativa, deixando claro que enquanto investigador tinha o interesse em dar voz a todos aqueles que "davam vida" à IAA.

Além disso, o investigador foi capaz de criar proximidade com alguns beneficiários, o que lhe permitiu cumprir com os objetivos do projeto. Esta proximidade advinha, por um lado, da capacidade de ouvir e de mostrar interesse pelo que era dito e, por outro, da disponibilidade dos beneficiários. Apesar dos breves momentos de interação que eram permitidos pelo trabalho realizado - entrega de bens alimentares - era possível lançar pequenos estímulos (ex: “hoje está um dia muito frio, não está?") que possibilitavam promover o diálogo. Também a adoção de uma postura calma e recetiva, contrastante em alguns casos com a postura de outros voluntários, conduziu a interessantes conversas sobre vidas marcadas pelos fenómenos supracitados, mas também por conquistas e vitórias. 
Em diversas situações, o investigador optava por se dirigir mais cedo para a IAA e/ ou sair mais tarde dela de forma a ter a possibilidade de conversar com os beneficiários; não raras vezes estes momentos eram valorizados através de frases como "muito obrigado por me ter ouvido". Esta estratégia contribuiu, não só, para a criação de proximidade e obtenção de informação útil para a pesquisa, como também para facilitar a prossecução do trabalho voluntário.

Estes esforços para criar empatia com os beneficiários assentaram numa lógica de partilha recíproca, na medida em que o investigador também partilhava aspetos da sua vida sempre que lhe parecia apropriado. Tal processo de troca de experiências parece aproximar-se do conceito de mutualidade enquanto uma "revelação partilhada" que, de certa forma, "sustenta o próprio conhecimento etnográfico" (Viegas e Mapril, 2012, p. 513).

Denota-se, portanto, a possibilidade de compatibilizar uma espécie de estranheza/ afastamento inicial com a criação de empatia e proximidade, tratando-se de um investimento em duas "frentes": por parte do voluntário/investigador e por parte dos beneficiários.

\section{As emoções}

A gestão das emoções que emergem no contacto com o terreno acarreta um conjunto de desafios. O investigador que procura explorar um campo de análise que se cruze com a sensibilidade do tema e com a vulnerabilidade dos participantes pode ver-se confrontado com situações que coloquem em causa o seu bem-estar psicológico.

Ainda que as emoções estejam presentes sempre que a investigação envolve o contacto com o outro, o impacto emocional que uma pesquisa pode ter para o investigador carece de análise. Trata-se de um campo pouco explorado e, de certa forma, ignorado (Melrose, 2002; Vincett, 2018). Porém, tal como é referido por Brannan (2014) é tão importante analisar o impacto da investigação para o sujeito investigado como para o investigador. Além disso, a existência de um reduzido número de estratégias na literatura que permitam ao investigador lidar com os desafios emocionais da pesquisa (Vincett, 2018) conduz a que ele tenha de criar as suas próprias estratégias e com base na sua experiência ir identificando aquilo que resulta.

Desta forma, o investigador estará mais predisposto a cometer erros durante a prossecução da pesquisa e estará menos preparado para lidar com o trabalho emocional decorrente da mesma. Nos casos mais extremos, pode enfrentar, por exemplo, esgotamento, fadiga, trauma ou estresse pós-traumático (Vincett, 2018; Warden, 2013).

Apesar da construção do projeto ter incluído a sensibilidade do tema e a vulnerabilidade dos participantes, sobretudo a nível metodológico, foi no contacto com a 
primeira IAA, durante o período exploratório, que o investigador se apercebeu do impacto emocional que a investigação viria a ter. Dos vários desafios emocionais com que o investigador se deparou no terreno, é possível destacar três, essencialmente, pela transversalidade que apresentam face às três iniciativas analisadas e pelo elevado nível de desgaste (emocional) provocado.

Um primeiro desafio relaciona-se com a gestão de conflitos no seio das IAA's, particularmente entre beneficiários. Tanto no interior das iniciativas analisadas, como nas zonas circundantes, os beneficiários interagem entre si, conversando sobre os mais variados temas. Não raras vezes, tais interações podem conduzir a desavenças, cabendo aos voluntários intervir, de forma mais ou menos direta, chamando, por exemplo, as autoridades competentes, caso a situação o justifique. Geralmente, os conflitos estão associados a questões: i) pessoais, ii) ligadas à própria iniciativa (ex: não respeitar a fila de espera) e/ou iii) ligadas a alterações do estado de espírito causadas pelo consumo de álcool e outras drogas. Todos estes episódios conduzem a que o voluntário tenha de tomar decisões num curto espaço de tempo de forma a pacificar a situação, provocando elevados níveis de stress.

O segundo desafio insere-se, de certa forma, no âmbito do primeiro, mas apresenta algumas particularidades que importam explorar. Ele diz respeito à gestão dos bens alimentares/refeições realizada pelos voluntários. Um dos grandes obstáculos que as IAA's enfrentam prende-se com a carência de alimentos/refeições que lhes permitam satisfazer a procura, desta forma as iniciativas têm que criar mecanismos que lhes permitam otimizar os recursos disponíveis. Nas várias IAA's analisadas, eram fornecidas diretrizes aos voluntários acerca do número de bens alimentares/refeições a que cada beneficiário/família tinha direito. Apesar da existência destas regras e de as mesmas serem difundidas, era habitual existirem processos de negociação entre beneficiário e voluntário. Tais processos implicavam um desgaste emocional considerável, uma vez que cabia ao voluntário a tarefa, ingrata, de negar ou restringir o acesso a comida a alguém que se encontrava a passar por dificuldades. Tais negociações podiam, em situações mais extremas, envolver ofensas verbais e ameaças à integridade física do voluntário, conforme foi relatado e testemunhado pelo investigador.

Além do impacto emocional decorrente do voluntariado, também é importante referir que o ato continuado de conduzir entrevistas sobre temas sensíveis com pessoas que se encontram numa situação de vulnerabilidade e, em certos casos, extremamente fragilizadas também pode conduzir a cansaço e a um forte desgaste emocional, representando este o terceiro desafio. Conduzir um elevado número de entrevistas que incidam sobre realidades difíceis e complexas pode também conduzir o investigador a que perca a capacidade para criar empatia e se torne "insensível" 
face às situações que lhe são descritas, uma preocupação identificada por Booth e Booth (1994) e Bahn e Weatherill (2012).

Face a isto, o investigador recorreu à literatura e ao conhecimento de cientistas sociais mais experientes e encontrou algumas estratégias. Partilhou as suas frustrações e ansiedades com colegas e familiares mais próximos; "partilhou" com o gravador, enquanto realizava as notas de campo, o que sentia sem se autocensurar; iniciou a prática de deporto; e começou a participar em eventos científicos que promovessem a partilha de experiências de investigação em torno da sensibilidade do tema e da vulnerabilidade dos participantes.

Trata-se de estratégias que resultam face a um contexto específico, mas que podem encontrar "pontes" com outras experiências de investigação. Ainda que algumas delas sejam possíveis de encontrar na literatura, como por exemplo a importância de escrever de forma livre e sem julgamentos apontada por Newman (2016), não existe consenso nem um corpo organizado e definido de conhecimentos.

Importa também referir a importância que tem para a investigação que o investigador, em certos momentos, seja capaz de se afastar da realidade estudada para que possa interpretar os dados com algum distanciamento. Preocupações estas expressas por Cannon (1989) e Lawton (2001). Tal distanciamento pode advir do estabelecimento de fases de investigação interrelacionadas, mas que se "esgotam" num dado momento. No âmbito do projeto de investigação, após o trabalho de campo ter sido concluído, o investigador deixou de realizar voluntariado nas IAA's para se dedicar ao tratamento dos dados e à sua interpretação. Mais do que uma preocupação ligada à gestão do tempo, o investigador apercebeu-se da necessidade de deixar de olhar para os dados a partir "de dentro" - enquanto investigador que realizou voluntariado e lidou com situações complexas - e começar a olhá-los a partir "de fora", focando-se, para tal, na literatura em torno do seu tema e nos novos sentidos e significados que ele pode retirar dela para compreender os fenómenos observados e vivenciados.

\section{O consentimento informado}

Ainda que a questão da aplicação do consentimento informado se coloque em torno de, praticamente, todo o tipo de pesquisas que são realizadas no âmbito das ciências sociais, no caso da investigação em torno de temas sensíveis e grupos vulneráveis, esta questão ganha particular ênfase.

Se no decorrer de uma investigação existem determinados princípios que devem ser salvaguardados, como o da voluntariedade de fornecimento de informação e o direito à privacidade e ao anonimato, no caso dos temas sensíveis e grupos vulneráveis estes aspetos tornam-se centrais, uma vez que é pedido "aos informantes ou 
respondentes que partilhem informação íntima ou que os pode incriminar" (Lee e Renzetti, 1990, p. 517 - tradução livre).

Um dos grandes desafios em lidar com temas sensíveis e populações vulneráveis prende-se, justamente, com a dificuldade de garantir que todos os requisitos éticos e legais sejam cumpridos, onde interessa - entre outros procedimentos obter o consentimento dos participantes (Hilário, 2009).

Uma das fases mais críticas, enquanto teste à relação investigador-investigado, prende-se com a forma como a investigação é explicada aos participantes e como o consentimento informado - a contratualização da relação em causa - é aplicado e, portanto, dado a conhecer. Esta forma de contrato incorpora um conjunto de direitos (do participante) - por exemplo: o direito de desistir a qualquer momento - e de responsabilidades (do investigador) - por exemplo: de garantir a confidencialidade e o anonimato - que estarão presentes durante todo o processo de pesquisa (Hilário, 2009, 2015).

Exatamente por se tratar de um contrato e, portanto, de um processo burocrático com algum formalismo, a sua apresentação pode gerar desconfiança junto dos participantes (São José e Teixeira, 2013). Por outro lado, em última análise, trata-se sempre de uma ferramenta incompleta, na medida em que o investigador não consegue antever todas as situações e todos os riscos que poderão advir da investigação (Hilário, 2009). Talvez por isso os consentimentos sejam, em certos casos, caracterizados por uma certa ambiguidade, falta de clareza e objetividade, o que também pode contribuir para gerar desconfiança.

No âmbito da investigação que tem vindo a ser desenvolvida, o modelo de consentimento informado foi apresentado aos responsáveis das IAA's aquando da assinatura do protocolo de cooperação e da entrega de outros documentos informativos do projeto.

O modelo em causa - baseado num consentimento aplicado no âmbito de um projeto internacional financiado pelo European Research Council (ERC) - é constituído por um conjunto de afirmações inseridas numa grelha, sendo suposto que o participante assinale com uma cruz se concorda ou não com aquilo que é afirmado. Na parte final do documento é pedido ao participante e ao investigador que assinem e coloquem a data. Os últimos elementos a constar no documento prendem-se com informações de contacto, bem como informações relativas às entidades financiadoras do projeto.

As afirmações presentes no consentimento dividem-se em três grupos: i) informação relativa ao projeto e ao que irá ser pedido ao participante; ii) informação relativa ao uso que irá ser feito dos dados recolhidos; e iii) informação relativa ao tratamento e processo de arquivo dos dados. 
No momento em que o investigador contactou com os participantes, optou por relembrar os mesmos sobre a existência do projeto, descrevendo-o em traços gerais, e por explicar em que consistia a entrevista. Após esta breve explicação, caso houvesse interesse em participar, a entrevista era agendada em horário e local determinados pelos participantes. Relativamente à escolha do local, o investigador apercebeu-se que se poderia tratar de um bom indicador do nível de confiança que os entrevistados tinham para com ele, sendo que um grande número de entrevistas ocorreu em espaços públicos, como jardins, bibliotecas ou nas próprias IAA`s. Um número reduzido de participantes aceitou dirigir-se ao instituto que acolhe o doutorando. Num dos casos, o nível de desconfiança seria tão elevado que a entrevista foi realizada e mediada por um assistente social.

Durante as entrevistas, o investigador procurava, numa primeira fase, estabelecer um diálogo amigável, falando do tempo, do percurso que havia sido realizado ou de alguma notícia que estivesse em voga. Após estes pequenos diálogos introdutórios, que permitiam deixar os participantes confortáveis com a situação, o investigador começava por relembrar o projeto, os seus objetivos e por explicar o consentimento informado, apresentando o mesmo.

No decorrer do preenchimento, o investigador deparou-se com alguns participantes que referiam não necessitar de ler o consentimento, perguntado apenas onde deviam assinar. Face a estes participantes, optou-se por aplicar o consentimento de outra forma, lendo as afirmações realizadas e pedindo uma resposta. Ainda que tenham existido situações em que os participantes ofereciam alguma resistência à explicação do consentimento, procurou-se sempre dar conta da importância de conhecer o documento que estava a ser assinado. O contacto prévio com os participantes, através do voluntariado, bem como a criação de um ambiente que não fosse demasiado formal contribuiu para que a aplicação do documento em causa tivesse ocorrido de forma fluída.

Contudo, e tendo em conta que existem dois momentos de recolha de dados - observação participante e as entrevistas - , como pensar a aplicação do consentimento no primeiro momento? De facto, esta interrogação representou, desde cedo, uma preocupação para o investigador. Saber como iria informar todos os beneficiários e voluntários que participassem na pesquisa de forma mais ou menos direta conduziu à necessidade de adotar uma estratégia diferente face àquela que foi seguida para as entrevistas.

Indo ao encontro das recomendações presentes no documento "Research Ethics in Ethnography/ Anthropology" (Iphofen, 2015), optou-se por incorporar no desenho de pesquisa o modelo de consentimento verbal, onde é explicado aos participantes o projeto e o duplo papel assumido pelo investigador na organização. Os 
participantes eram informados da existência de notas de campo, resultantes das observações realizadas. Também era explicado que as informações presentes nas notas não permitiam identificar os atores das situações que eram selecionadas e relatadas pelo investigador.

Como se pode constatar, a aplicação do consentimento informado representa um processo complexo que conduz a que o investigador se adapte às necessidades dos participantes e do contexto em que eles se inserem. Trata-se de uma ferramenta importante, na medida em que estabelece os moldes em que a interação investigador-investigado irá "operar" e que protege todos os intervenientes através da salvaguarda dos seus interesses.

\section{Reflexões finais}

Ignorar os desafios que são inerentes a uma investigação que incide sobre temas sensíveis e grupos vulneráveis, particularmente no que concerne às questões éticas e metodológicas, acarreta potenciais riscos para todos os agentes envolvidos e para a própria pesquisa, estando em causa a integridade física e psicológica dos primeiros e o rigor científico da segunda.

Neste sentido, é importante que o investigador incorpore no desenho de pesquisa estratégias que permitam responder aos desafios que advêm da sensibilidade dos temas e da vulnerabilidade dos participantes (Vincett, 2018). O primeiro desafio passa, justamente, por identificar estes elementos, sendo que a sensibilidade se pode manifestar pela existência de consequências - desde desconforto a ameaças à integridade física - para os atores investigados (Lee e Renzetti, 1990; Sieber e Stanley, 1988), por sua vez, a vulnerabilidade pode ser expressa através da perda de autonomia para tomar decisões (Moore e Miller, 1999; Silva, 1995).

Além deste primeiro desafio de ordem conceptual, considerou-se pertinente explorar, no presente artigo, o acesso ao terreno, o estatuto de voluntário, a gestão das emoções e a aplicação do consentimento informado. Desafios estes que emergiram no âmbito de uma pesquisa, de carácter eminentemente qualitativo, que incide sobre a análise de iniciativas de apoio alimentar a atuar em Portugal e dos seus atores.

Uma estratégia a que diversos investigadores têm recorrido para realizar investigação dentro de uma determinada organização prende-se com a prática de voluntariado (Martin, 2014; Merrell e Williams, 1994; Watts, 2011); desta forma, o investigador tem algo para oferecer em troca dos dados que pretende recolher (O'Connor e Baker, 2017). Trata-se de uma estratégia assente na reciprocidade que pode facilitar a entrada no terreno e a captação de determinadas dinâmicas sociais 
que seriam invisíveis ao investigador enquanto elemento totalmente externo à realidade estudada.

Porém, esta estratégia acarreta, também ela, um conjunto de desafios, onde se destaca a forma como o estatuto de voluntário pode contribuir para criar distanciamento para com alguns dos participantes. Questão que pode ser ultrapassada através do diálogo e, portanto, do tipo de relação que o investigador seja capaz de estabelecer.

A gestão das emoções do investigador em contexto de pesquisa representa um campo ainda pouco explorado na literatura (Melrose, 2002; Vincett, 2018). A promoção de um debate alargado em torno da criação e aplicação de estratégias que permitam lidar com os desafios emocionais que decorrem do contacto com realidades caracterizadas pela sensibilidade e vulnerabilidade podem contribuir para a difusão de mecanismos de resiliência.

Também no âmbito das iniciativas analisadas denotou-se a inexistência de ferramentas práticas que permitam aos voluntários lidar com os desafios emocionais com que se podem deparar no terreno. A grande maioria dos voluntários com quem o investigador interagiu, durante o trabalho de campo, apontaram a falta de formação como uma das principais lacunas da iniciativa em que se encontravam, sendo esta ideia transversal às várias IAA's. Neste sentido, considera-se importante sensibilizar os responsáveis das iniciativas para esta carência e para a importância de dar a conhecer aos voluntários, por um lado, os potenciais riscos a que estão sujeitos, por outro, estratégias para os combater/minimizar.

A existência de relações de poder em contexto de entrevista e no âmbito de uma pesquisa etnográfica pode assumir um carácter mais ou menos visível dependendo da forma como a interação é negociada (Chen, 2011; Wolf, 1996). A posição privilegiada do investigador é potencialmente geradora de dinâmicas de dominação, sendo que a aplicação do consentimento informado pode acentuar tais dinâmicas e colocar em causa o desenrolar da pesquisa e das relações que ela promove (Hilário, 2009; Plankey-Videla, 2012). Desta forma, o investigador possui a responsabilidade de aplicar esta ferramenta de forma transparente, adequando, sempre que necessário, o modelo de consentimento e a forma como o mesmo é apresentado consoante o contexto em que se insere.

Em suma, realizar investigação sobre temas sensíveis com grupos vulneráveis implica dar resposta a um alargado conjunto de desafios que variam consoante o contexto e a situação. Desta forma, cabe ao investigador tomar as decisões, tendo em conta a sua bagagem (teórica e conceptual) e o seu discernimento. Contudo, a partilha de experiências de investigação e, portanto, dos sucessos e insucessos que as caracterizam - exercício que se procurou realizar no presente artigo - pode 
contribuir para a criação de estratégias que vão ao encontro das reais necessidades da pesquisa.

\section{Agradecimentos}

O autor agradece o apoio financeiro concedido pela Fundação para a Ciência e a Tecnologia (FCT) através da atribuição de uma bolsa de investigação, com a referência SFRH/BD/130072/2017, no âmbito do Programa Operacional Capital Humano (POCH), comparticipado pelo Fundo Social Europeu (FSE) e por fundos nacionais do Ministério da Ciência, Tecnologia e Ensino Superior (MCTES).

\section{Nota}

Por decisão pessoal, o autor do texto escreveu segundo o novo acordo ortográfico.

1 O projeto contempla, numa primeira fase, a análise de dados secundários, onde se procura caracterizar a realidade portuguesa enquadrando-a no contexto europeu no que diz respeito à prevalência da pobreza alimentar, bem como à distribuição e caracterização das IAA’s.

\section{Referências}

Amante, M. (2015). A escolha do terreno: Ruralidade, familiaridade e reflexividade na construção dos terrenos etnográficos. Análise Social, 217(4), 810-829.

Augusto, F. R., e Hilário, A. P. (2019). 'Through the looking glass': The emotional journey of the volunteer ethnographer when researching sensitive topics with vulnerable populations. The Qualitative Report, 24(13), 17-30.

Bahn, S., e Weatheril, P. (2012). Qualitative social research: A risky business when it comes to collecting 'sensitive' data. Qualitative Research, 13(1), 19-35.

Berger, R. (2017). Conducting an unplanned participant observation: The case of a non-birder in bird watcher's land. Forum: Qualitative Social Research, 18(1), 1-14.

Booth, T., e Booth, W. (1994). The use of depth interviewing with vulnerable subjects: Lessons from a research study of parents with learning difficulties. Social Science e Medicine, 39(3), 415-424.

Brannan, M. J. (2014). Recognizing research as an emotional journey. Em C. Clarke, M. Broussine, e L. Watts (Eds.), Researching with feeling: The emotional aspects of social and organizational research (pp. 17-34). Londres: Routledge.

Bryman, A. (2012). Social research methods. Nova Iorque: Oxford University Press.

Burgess, R. (1997). A pesquisa de terreno: Uma introdução. Oeiras: Celta Editora. 
Calnitsky, D. (2018). Structural and individualistic theories of poverty. Sociology Compass, 12(12), 1-14.

Cannon, S. (1989). Social research in stressful settings: Difficulties for the sociologist studying the treatment of breast cancer. Sociology of Health and Illness, 11(1), 62-77.

Chen, S. H. (2011). Power relations between the researcher and the researched: An analysis of native and nonnative ethnographic interviews. Field Methods, 23(2), 119-135.

Depa, J., Gyngell, F., Muller, A., Eleraky, L., Hilzendegen, C., e Stroebele-Benschop, N. (2018). Prevalence of food insecurity among food bank users in Germany and its association with population characteristics. Preventive Medicine Reports, 9, 96-101.

Dickson-Swift, V., James, E., e Liamputtong, P. (2008). Undertaking sensitive research in the health and social sciences: Managing boudaries, emotions and risks. Cambridge: Cambridge University Press.

Duelli-Klein, R. (1983). How to do what we want to do: Thoughts about feminist methodology. Em G. Bowles, e R. Dueli-Klein (Eds.), Theories of women's studies (pp. 88-105). Londres: Routledge e Kegan Paul.

Gold, R. (1997). The ethnographic method in sociology. Qualitative Inquiry, 3(4), 388-402.

Hennequin, E., e Condomines, B. (2014). Studying sensitive issues: The contributions of a mixed approach. RIMHE: Revue Interdisciplinaire Management, Homme e Entrepise, 14, 3-19.

Hilário, A. (2009). Journeys into end of life research: Some methodological considerations (CIES e-Working Papers, $n^{\circ}$ 82). Lisboa: CIES.

Hilário, A. (2015). Making sense of a changed physical body: Why gender matters at end of life. Journal of Aging Studies, 33, 58-66.

Iphofen, R. (2015). Research ethics in ethnography/anthropology. Bruxelas: European Commission, DG Research and Innovation.

Johnson, B., e Clarke, J. (2003). Collecting sensitive data: The impact on researchers. Qualitative Health Research, 13(3), 421-434.

Lawton, J. (2001). Gaining and maintaining ethical concerns raised in a study of dying patients. Qualitative Health Research, 11(5), 693-705.

Lee, R., e Renzetti, C. (1990). The problems of researching sensitive topics: An overview and introduction. American Behavioral Scientist, 33(5), 510-528.

Lee, R., e Renzetti, C. (1993). The problems of researching sensitive topics. Em C. Renzetti, e R. Lee (Eds.), Researching sensitive topics (pp. 3-13). Newbury Park: Sage Publications.

Liamputtong, P. (2007). Researching the vulnerable. Londres: Sage.

Loopstra, R., e Lalor, D. (2017). Financial insecurity, food insecurity, and disability: The profile of people receiving emergency food assistance from The Trussell Trust Foodbank Network in Britain. Salisbury: The Trussell Trust.

Marsh, C., Browne, J., Taylor, J., e Davis, D. (2017). A researcher's journey: Exploring a sensitive topic with vulnerable women. Women and Birth, 30, 63-69. 
Martin, N. (2014). Spaces of hidden labor: Migrant women and work in nonprofit organizations. Gender, Place and Culture: A journal of Feminist Geography, 21(1), 17-34.

Martins, P., Oliveira, V., e Tendais, I. (2018). Research with children and young people on sensitive topics - The case of poverty and delinquency. Childhood, 0(0), 1-15.

Melrose, M. (2002). Labour pains: Some considerations on the difficulties of researching juvenile prostitution. International Journal of Social Research Methodology, 5(4), 333-351.

Merrell, J., e Williams, A. (1994). Participant observation and informed consent: Relationships and tactical decision making in nursing research. Nursing Ethics, 1(3), 163-172.

Mirosa, M., Mainvil, L., Horne, H., e Magan-Walker, E. (2016). The social value of rescuing food, nourishing communities. British Food Journal, 118(12), 3044-3058.

Moore, L., e Miller, M. (1999). Initiating research with doubly vulnerable populations. Journal of Advanced Nursing, 30(5), 1034-1040.

Mulhall, A. (2003). In the field: Notes on observation in qualitative research. Journal of Advanced Nursing, 41(3), 306-313.

Newman, K. M. (2016, 9 de novembro). Five science-backed strategies to build resilience. Greater Good Science Center. Science-Based Insights for a Meaningful Life. Disponível em https://greatergood.berkeley.edu/article/item/five_science_backed_strategies_to_bu ild_resilience.

O'Connor, C., e Baker, R. (2017). Working with and for social enterprises the role of the volunteer ethnographer. Social Enterprise Journal, 13(2), 180-193.

Plankey-Videla, N. (2012). Informed consent as process: Problematizing informed consent in organizational ethnographies. Qualitative Sociology, 35(1), 1-21.

São José, J., e Teixeira, A. (2013). At the 'ethical crossroads' of ethnography: Observing the 'care encounter' at the elderly person's home. Em I. Paoletti, M. Tomás, e M. Menendéz (Eds.), Practice of ethics: An empirical approach to ethics in social science research (pp. 43-63). Newcastle: Cambridge Scholar Publishing.

Schweiger, G., e Graf, G. (2015). A philosophical examination of social justice and child poverty. Houndsmills: Palgrave Macmillan.

Seigel, K., e Bauman, L. (1986). Methodological issues in AIDS-related research. In D. Feldman, e T. Johnson (Eds.), The social dimensions of AIDS (pp. 15-39). Nova Iorque: Praeger.

Sieber, J., e Stanley, B. (1988). Ethical and professional dimensions of socially sensitive research. American Psychologist, 43, 49-55.

Silva, M. (1995). Ethical guidelines in the conduct, dissemination and implementation of nursing research. Washington, DC: American Nurses Publishing.

Spradley, J. (1980). Participant observation. Londres: Wadsworth.

Stroebele-Benschop, N., Simmet, A., e Depa, J. (2017). Nutrition status of those receiving unprepared food from food banks: Overview of food bank users in high-income countries and their diet. Em V. Preedy, e V. B. Patel (Eds.), Handbook of famine, starvation, and nutrient deprivation: From biology to policy (pp. 1-22). Cham: Springer International Publishing. 
Van der Horst, H., Pascucci, S., e Bol, W. (2014). The 'dark side' of food banks? Exploring emotional responses of food bank receivers in the Netherlands. British Food Journal, 116(9), 1506-1520.

Viegas, S., e Mapril, J. (2012). Mutualidade e conhecimento etnográfico. Etnográfica, 16(3), 513-524.

Vincett, J. (2018). Researcher self-care in organizational ethnography: Lessons from overcoming compassion fatigue. Journal of Organizational Ethnography, 7(1), 44-58.

Vlaholias, E., Thompson, K., Every, D., e Dawson, D. (2015). Charity starts... at work? Conceptual Foundations for research with businesses that donate to food redistribution organizations. Sustainability, 7, 7997-8021.

Waddington, D. (1994). Participant observation. In C. Cassell, e G. Symon (Eds.), Qualitative Methodology in Organizational research: A practical guide (pp. 107-122). Londres: Sage.

Warden, T. (2013). Feet of clay: Confronting emotional challenges in ethnographic experience. Journal of Organizational Ethnography, 2(2), 150-172.

Watts, J. (2011). Ethical and practical challenges of participant observation in sensitive health research. International Journal of Social Research Methodology, 14(4), 301-312.

Wellings, K., Branigan, P., e Mitchell, K. (2000). Discomfort, discord and discontinuityas data: Using focus groups to research sensitive topics. Culture, Health e Sexuality, 2(3), 255-267.

Wolf, D. L. (1996). Feminist dilemmas in fieldwork. Boulder: Westview.

Data de submissão: 25/02/2019 | Data de aceitação: 28/03/2019 